\title{
A Multiobjective Decision-Making Method of Service Element Allocation of Customer Behavior
}

\author{
Wei Xu $\mathbb{D}$, Yinyun Yu $\mathbb{D}$, and Qingshan Zhang \\ School of Management, Shenyang University of Technology, No. 111, Shenliao West Road, Economic \& Technological Development Zone, \\ Shenyang 110870, China \\ Correspondence should be addressed to Yinyun Yu; 3035905183@qq.com
}

Received 16 September 2017; Accepted 14 January 2018; Published 14 February 2018

Academic Editor: Guang Zhang

Copyright (C) 2018 Wei Xu et al. This is an open access article distributed under the Creative Commons Attribution License, which permits unrestricted use, distribution, and reproduction in any medium, provided the original work is properly cited.

\begin{abstract}
How to effectively configure the resources to maximize customer satisfaction is an important research topic in the service quality evaluation. This paper proposes a service quality evaluation under fuzzy environment method that takes customer satisfaction as the goal and considers enterprise resource constraints and customer fuzzy evaluation information at the same time. In this method, we first use expert Delphi method to get service elements and service items. Meanwhile, we design questionnaires to collect customer language fuzzy evaluation information and use FHAHP model to calculate the relative weight vector of the service items. Second, the customer is subdivided into market segmentation considering the customer total consumption and the service expectation value using the Logit model. Next, the customer satisfaction of the service schemes is calculated considering the customer's expectation of the service schemes. Then, the maximum satisfaction of the customer group is calculated under the condition of enterprise resource constraint. Finally, an example is used to illustrate the feasibility and effectiveness of the proposed method.
\end{abstract}

\section{Introduction}

To retain stability and competitiveness in such a global dynamic market, service-oriented enterprises should focus on the quality of service in order to achieve sustainable development of its benefits. Service quality is consumers' overall impression of the relative inferiority or superiority of service-oriented enterprises [1], providing high-quality service products for service-oriented enterprises to better hold market share and gain greater profits [2]. Under the condition of enterprise resource and cost constraint, it is very important for the development of enterprises to maximize satisfy customer needs and improve customer satisfaction. Hallikas et al. posited that in a highly competitive environment service-oriented enterprises need to improve service quality continuously for maintaining competitive advantage [3]. It is vital to service-oriented enterprises growth by effectively optimizing and assessing service programs to mitigate the barriers [4]. Service quality evaluation will provide an important basis for service quality improvement.

The issue of service quality evaluation has received considerable attention from researchers and practitioners during the past three decades. In the extant literature there are a number of studies that deal with service quality evaluation, which can be divided into two groups: one is the SERVPERF model proposed by Cronin Jr. and Taylor [5]; another is SERVQUAL (the service quality gaps model PZB gap model), a well-known measure, proposed by Parasuraman et al. [6]. The existing literature methods mainly focus on the importance analysis of the service elements, service scheme design and service system design, and service product quality evaluation. However, the service quality evaluation based on fuzzy environment is very little.

Moreover, service quality evaluation is a combination of various attributes; it contains not only objective attributes but also subjective attributes, many of which are intangible and difficult to measure with numerical accuracy, which are fuzzy information [7]. This paper proposes a novel method for customer satisfaction service quality evaluation under fuzzy environment. The remaining sections of the paper are organized as follows: Section 2 reviews some of the existing research results of the service quality evaluation. Section 3 proposes a novel method for evaluating the service quality under fuzzy environment. An illustrative example is 
given to demonstrate the use of the proposed method in Section 4. Finally, the conclusion of this paper on the original contributions and suggested future work is drawn.

\section{Literature Review}

The extent to which the quality of service meets the requirements of the customer, that is, customer satisfaction [8], is the standard to measure the feasibility and quality of service products. After service is provided, a positive or negative reaction will emerge from customers getting that service [9]. Therefore, good customer satisfaction can improve customer loyalty and profitability and return on investment and guarantee the business success in today's competitive world. In recent years, the quality evaluation research results of customer satisfaction as the target are increasing, for example, Mkpojiogu and Hashim [10], based on the KANO model to analyze the relationship between customer need and customer satisfaction, and then the customer satisfaction is divided into customer satisfaction index (SI), average satisfaction coefficient (ASC), and customer dissatisfaction (DI). Through KANO model analysis customer satisfaction variables (SI, DI, and ASC) are each associated with customer need. George and Kumar explore service quality dimensions in Internet Banking in the State of Kerala (India) and investigate the effect of these dimensions on customer satisfaction, that is, the impact of five dimensions of reliability, responsiveness, fulfillment, efficiency, and privacy and security on customer satisfaction [1]. Chakraborty et al. [11] present an innovative approach to customer satisfaction service quality evaluation by applying Bayesian Networks, using a railway transport case study customer satisfaction, which is a Key Performance Indicator in public transport management.

Here are often some attributes that are difficult to quantify with a single value in the service quality evaluation; for example, it is difficult to quantify the freshness of food with a single value. In recent years, many researchers have introduced fuzzy values to service quality evaluation; for example, Li et al. [12] proposed a hybrid approach based on fuzzy AHP and 2-tuple fuzzy linguistic method to evaluate in-flight service quality. The ratings of subcriteria are assessed in linguistic values to express the qualitative evaluation of passengers' subjective opinions, and then the linguistic values are transformed into 2-tuples and the 2tuple linguistic arithmetic mean operator is utilized to obtain the average ratings of 100 respondents. Using the 2-tuple linguistic weighted average operator to compute the aggregated ratings of criteria and the overall in-flight service quality of alternatives, Büyüközkan and Çifçi [13] proposed the e-sq framework which is illustrated with a web service performance example of healthcare sector in Turkey by using a combined multiple criteria decision-making (MCDM) methodology containing fuzzy analytic hierarchy process (AHP) and fuzzy technique for order performance by similarity to ideal solution (TOPSIS). Chou et al. [14] proposed a fuzzy weighted SERVQUAL model for evaluating the airline service quality. Liao and Kao propose a novel approach to customer service management. For the improvement of customer satisfaction, the method integrates quality function development (QFD), fuzzy extended analytic hierarchy process (FEAHP), and multisegment goal programming (MSGP) [15].

According to the above review, this paper proposes a novel approach for customer satisfaction service quality evaluation under fuzzy environment.

\section{The Proposed Method}

The service elements are the basic components of the service quality evaluation, such as service facilities, service content, and service flow, which can meet the customer need. The customer need for the service can usually be divided into a number of service elements; there may be multiple replaceable service elements to meet customer need; these service elements can constitute a service item (i.e., a set of service elements that can be replaced with each other). Different service elements have a different degree of satisfaction to the customer's needs, and the corresponding cost should be different. Different service elements are optimized and combined to constitute different service schemes. Considering the service-oriented enterprise's objectives and capabilities, the quality of each service scheme is evaluated and the best service scheme is selected [16], as shown in Figure 1.

3.1. Problem Description. This paper proposes a novel approach for customer satisfaction service quality evaluation under fuzzy environment. In this method, first of all, the service items and service elements are obtained by Delphi method, and a questionnaire survey is designed to obtain the language evaluation information of the target customers. Because the language evaluation information is very vague, we use fuzzy extended analytic hierarchy process (FEAHP) model to calculate the relative weight vector of each service item. Then taking into account the effect of customer behavior on customer satisfaction, the Logit model is used to subdivide the customer market segmentation. Next, the customer satisfaction degree of each service scheme is calculated by considering the customer's expectation of the service schemes. On this basis, the customer maximum satisfaction is calculated under the consideration of the enterprise cost constraints. Finally, the service quality evaluation of China's high-speed rail was selected as an example to prove the feasibility and effectiveness of the proposed method.

$\mathrm{CN}=\left\{\mathrm{CN}_{1}, \mathrm{CN}_{2}, \ldots, \mathrm{CN}_{n}\right\}$. This is a collection of customer needs of service product, where $\mathrm{CN}_{t}$ denotes the $t$ th customer needs, $t=1,2, \ldots, n$.

$\mathrm{SO}=\left\{\mathrm{SO}_{1}, \mathrm{SO}_{2}, \ldots, \mathrm{SO}_{h}\right\}$. This is a collection of service schemes, where $\mathrm{SO}_{f}$ denotes the $f$ th service schemes, $f=$ $1,2, \ldots, h$.

$S_{j}=\left\{S_{j 1}, S_{j 2}, \ldots, S_{j k}\right\}$. It is the collection of the $j$ th service items, where $S_{j p}$ is the $p$ th service elements in the $j$ th service items, $j=1,2, \ldots, m, p=1,2, \ldots, k$. 


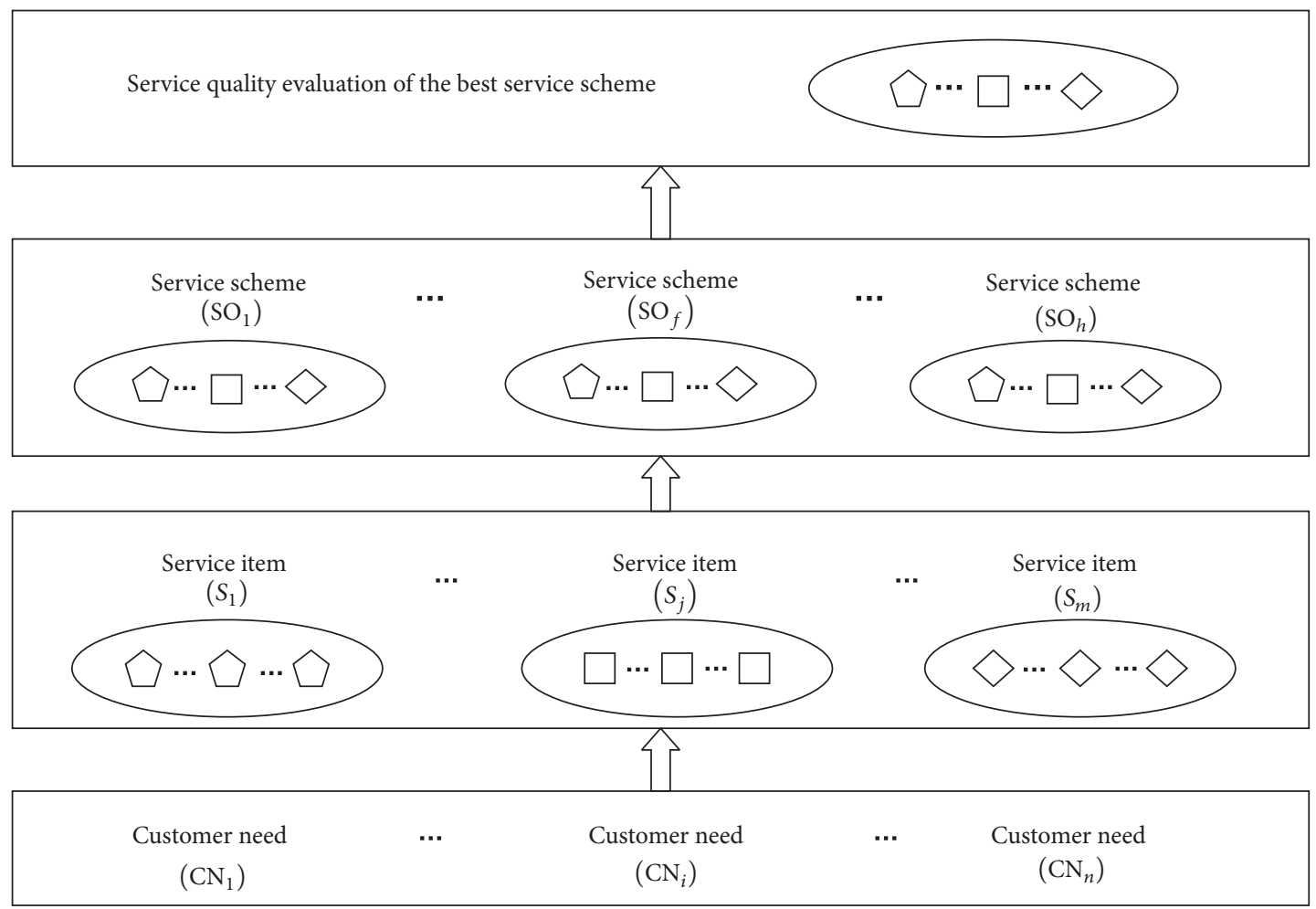

FIGURE 1: Optimal service plan formation diagram.

$V=\left\{v_{1}, v_{2}, \ldots, v_{m}\right\}$. It is the collection of the service utility decision part of the service items, where $v_{j}$ is the service utility decision part of the $j$ th service items $\left(S_{j}\right), j=$ $1,2, \ldots, m$. The service utility decision part is determined by the relevant characteristics of serviceable elements, the relevant characteristics of the customer, and other relevant variables.

$E=\left\{e_{1}, e_{2}, \ldots, e_{m}\right\}$. This is the collection of service utility random part of the service items, where $e_{j}$ is the service utility random part of the $j$ th service items $\left(S_{j}\right), j=1,2, \ldots, m$. The difference between the total service utility and the service utility decision part is service utility random part.

$R=\left[r_{i j}\right]_{n \times n}$. This is fuzzy judgment matrix, where $r_{i j}$ denotes that $S_{i}$ is more important than $S_{j}, i=1,2, \ldots, m, j=$ $1,2, \ldots, m$. In general, $r_{i j}$ can be given directly by the expert or service design team.

$Z_{d}=\left(z_{d 1}, z_{d 2}, \ldots, z_{d m}\right)^{T}$. It is the expected vector for each service given by the $d$ th customer, where $z_{d j}$ denotes that the $d$ th customer gives the expected value for the $j$ th service items $\left(S_{j}\right) . d=1,2, \ldots, r, j=1,2, \ldots, m$.

$H_{j}=\left(H_{j 1}, H_{j 2}, \ldots, H_{j m}\right)^{T}$. It is a collection of service schemes for implementing service item $S_{j}$, where $H_{j p}$ denotes the $p$ th service schemes of implementing service item $S_{j}$.

The problem concerned in this paper is how to maximize customer satisfaction, considering the cost constraints of the enterprise. To solve the service quality evaluation problem under fuzzy environment, we proposed a novel method for service quality evaluation based on FEAHP and Logit model which is presented graphically as shown in Figure 2.

Based on the framework for evaluating service quality, the details of the proposed method are presented as follows.

3.2. Relative Weight of Service Items Based on FHAHP. According to the survey, in the life, one customer needs often one or more service items to be satisfied, and there may be some connections between these multiple service items. In this paper, the fuzzy extended analytic hierarchy process (FHAHP) is used to determine the weight of service items. The traditional service quality evaluation often adopts the scoring method to collect customer evaluation information; however, there are some uncertain attributes in real life, and it is difficult to use a single value to evaluate the service quality. If the attributes are singled out by the traditional single scoring method, it will lead to the loss of customer evaluation information and ultimately affect the accuracy of the service quality evaluation. In order to effectively reduce the loss of customer evaluation information, the fuzzy extension of the analytic hierarchy process makes the calculation of the weight of the service item more reasonable $[17,18]$.

3.2.1. AHP Model of Service Quality. The AHP model of service quality includes three levels: the target layer, the guideline layer, and the factor layer. The target layer is to measure the service quality of service schemes. The guideline layer includes the service items that affect the service quality. 


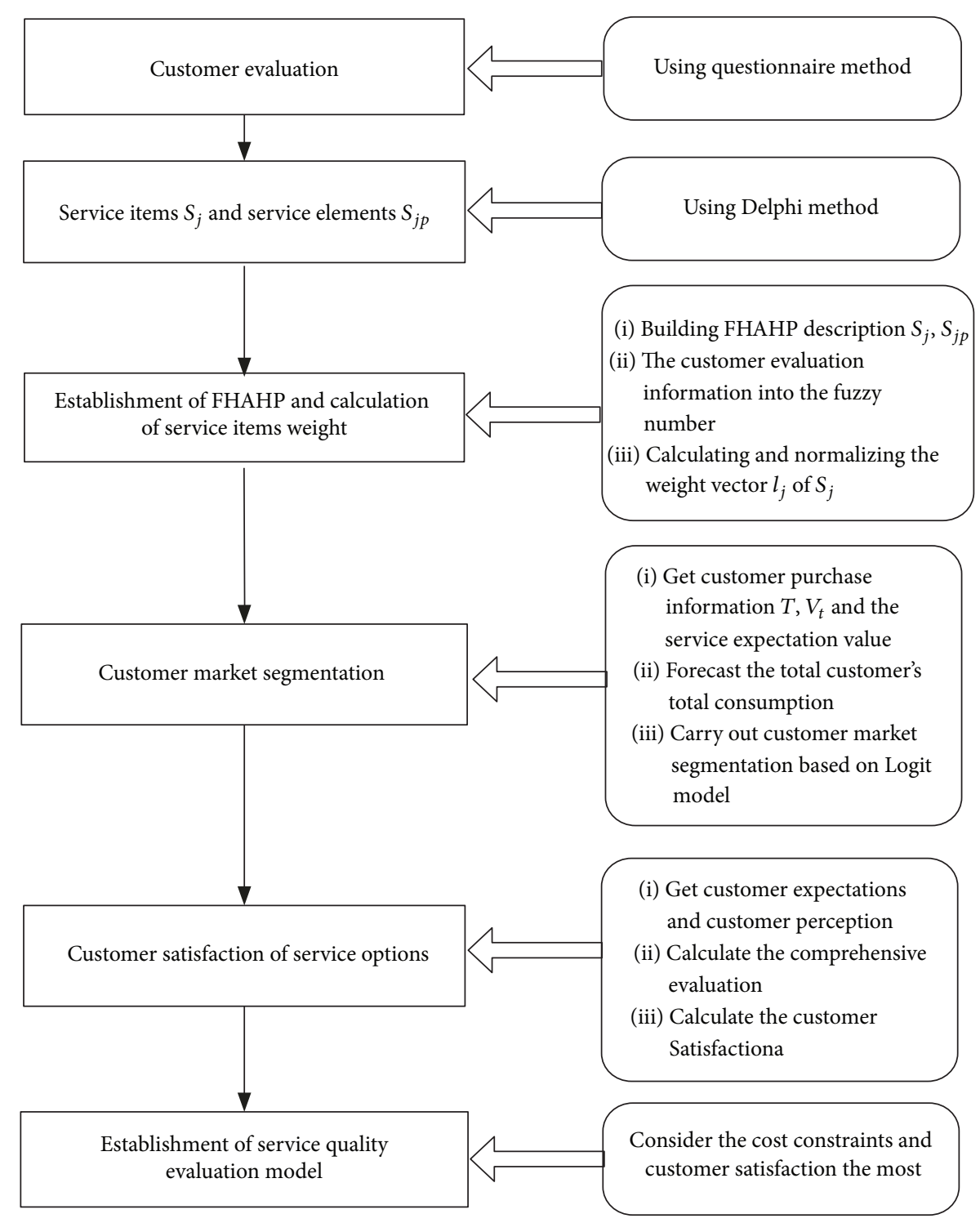

Figure 2: The framework of the proposed method.

The factor layer includes the specific service elements contained in each service item; it can be expressed in Figure 3.

\subsubsection{Fuzzy Judgment Matrix Established Based on the Fuzzy Numbers}

(1) The Triangular Fuzzy Numbers $[19,20]$. Let $X$ be a universe of discourse; a fuzzy subset $\widehat{a}$ of $X$ is defined with a membership function $v_{\widehat{a}}(x)$ that maps each element $x$ in $\widehat{a}$ to a real number in the interval $[0,1]$. The function value of $v_{\widehat{a}}(x)$ signifies the grade of membership of $x$ in $\widehat{a}$. When $v_{\widehat{a}}(x)$ is large, its grade of membership of $x$ in $\widehat{a}$ is strong.

A triangular fuzzy number $\widehat{a}$ can be defined by a triplet $\left(a^{L}, a^{M}, a^{R}\right), a^{L} \leq a^{M} \leq a^{R}$ (see Figure 4). Its membership function $v_{\widehat{a}}(x)$ is defined as

$$
v_{\widehat{a}}(x)= \begin{cases}0, & x<a^{L}, \\ \frac{x-a^{L}}{a^{M}-a^{L}}, & a^{L} \leq x \leq a^{M}, \\ \frac{a^{R}-x}{a^{R}-a^{M}}, & a^{M} \leq x \leq a^{R}, \\ 0, & x>a^{R},\end{cases}
$$

where $a^{L}, a^{M}$, and $a^{R}$ are real numbers. When $x=a^{M}$, the grade of $v_{\widehat{a}}(x)$ is maximal; that is, $v_{\widehat{a}}(x)=1$, and it is the most probable value of the evaluation data. Constants $a^{L}$ and $a^{R}$ are the lower and upper bounds of the available range for the evaluation data. These constants reflect the fuzziness of the evaluation data, as shown in Figure 4. 


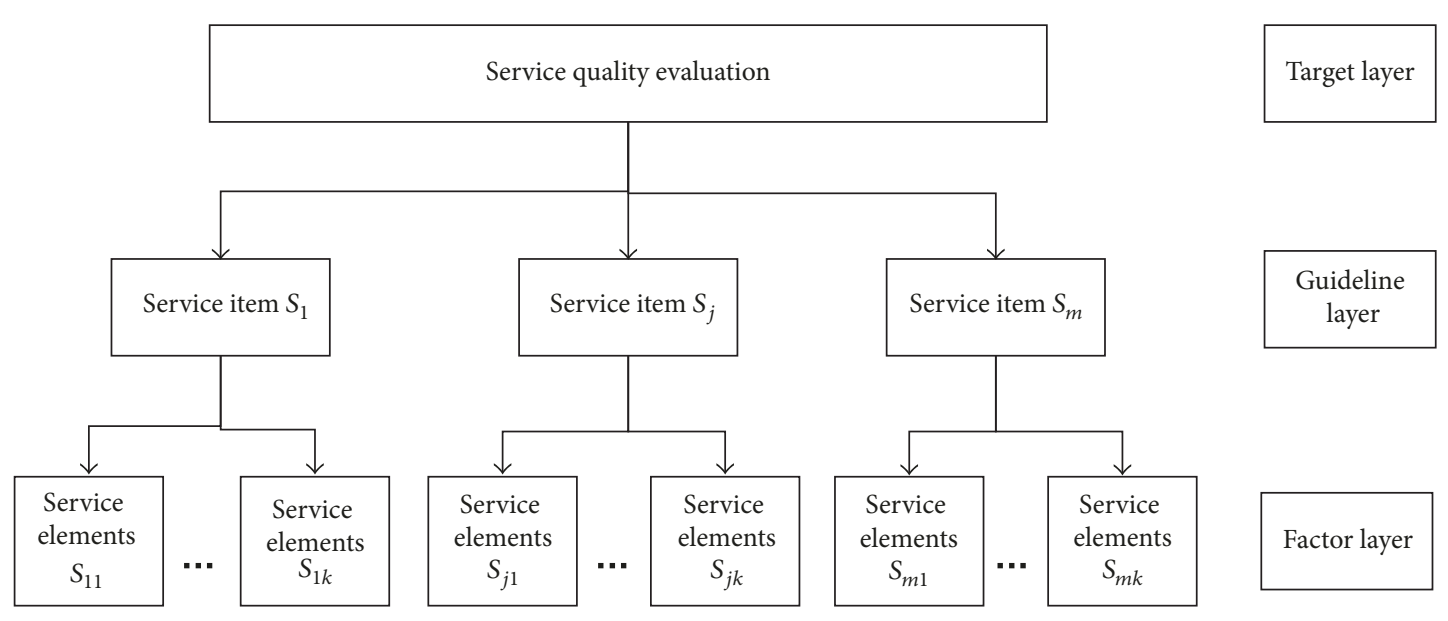

FIGURE 3: The framework of the proposed method.

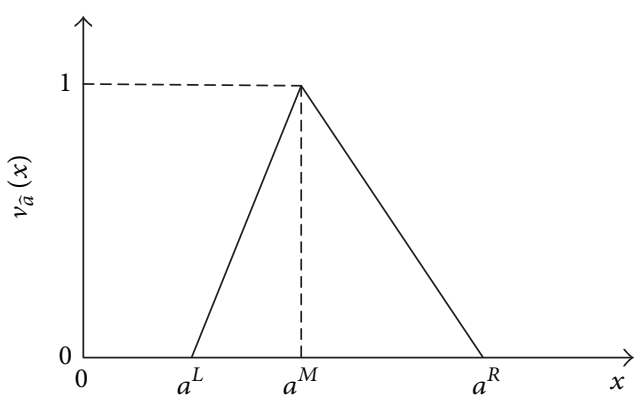

FIgURE 4: A triangular fuzzy number $\widehat{a}$.

Given two arbitrary triangular fuzzy numbers $\widehat{a}_{1}=$ $\left(a_{1}^{L}, a_{1}^{M}, a_{1}^{R}\right), \widehat{a}_{2}=\left(a_{2}^{L}, a_{2}^{M}, a_{2}^{R}\right)$ and any real number $\lambda$, let $\oplus, \odot$, $\otimes$, and / denote the extended addition, subtraction, multiplication, and division defined by the extension principle; thus the five main operations of triangular fuzzy numbers can be expressed as follows:

(i) $\widehat{a}_{1} \oplus \widehat{a}_{2}=\left(a_{1}^{L}+a_{2}^{L}, a_{1}^{M}+a_{2}^{M}, a_{1}^{R}+a_{2}^{R}\right), a_{1}^{L}>0, a_{2}^{L}>0$.

(ii) $\widehat{a}_{1} \odot \widehat{a}_{2}=\left(a_{1}^{L}-a_{2}^{R}, a_{1}^{M}-a_{2}^{M}, a_{1}^{R}-a_{2}^{L}\right), a_{1}^{L} \geq 0, a_{2}^{L} \geq 0$.

(iii) $\widehat{a}_{1} \otimes \widehat{a}_{2}=\left(a_{1}^{L} a_{2}^{L}, a_{1}^{M} a_{2}^{M}, a_{1}^{R} a_{2}^{R}\right), a_{1}^{L} \geq 0, a_{2}^{L} \geq 0$.

(iv) $\widehat{a}_{1} / \widehat{a}_{2}=\left(a_{1}^{L} / a_{2}^{R}, a_{1}^{M} / a_{2}^{M}, a_{1}^{R} / a_{2}^{L}\right), a_{1}^{L}>0, a_{2}^{L}>0$.

(v) $\lambda \otimes \widehat{a}_{1}=\left(\lambda a_{1}^{L}, \lambda a_{1}^{M}, \lambda a_{1}^{R}\right), a_{1}^{L} \geq 0, \lambda \geq 0$.

(2) Fuzzy Judgment Matrix Established. According to the overall goal requirements, through the two comparisons of services to obtain the fuzzy judgment matrix [21], the fuzzy judgment matrix is expressed as

$$
R=\left[r_{i j}\right]_{m \times m}, \quad i=1,2, \ldots, m, j=1,2, \ldots, m .
$$

Here, $r_{i j}=\left(a_{i j}{ }^{L}, a_{i j}{ }^{M}, a_{i j}{ }^{R}\right)$ is a triangular fuzzy number, $a_{i j}{ }^{L}, a_{i j}{ }^{R}$ are the upper and the lower bounds of the triangular fuzzy numbers, and $a_{i j}{ }^{M}$ is the relative importance of the digital measure between $a_{i j}{ }^{L}$ and $a_{i j}{ }^{R}, a_{i j}{ }^{L}<a_{i j}{ }^{M}<a_{i j}{ }^{R}$.
TABLE 1: AHP judgment scale definition table.

\begin{tabular}{lc}
\hline Judgment scale & Definition \\
\hline 0.9 & $r_{i}$ to $r_{j}$ is absolutely important \\
0.8 & $r_{i}$ to $r_{j}$ is strongly important \\
0.7 & $r_{i}$ to $r_{j}$ is obviously important \\
0.6 & $r_{i}$ to $r_{j}$ is slightly important \\
0.5 & $r_{i}$ to $r_{j}$ is equally important \\
$0.4,0.3,0.2,0.1$ & In contrast, the importance of $r_{j}$ to $r_{i}$ \\
\hline
\end{tabular}

Using the 0-1 scoring method to take the value of $a_{i j}{ }^{M}$, get the model judgment matrix $R$, as shown in Table 1.

When $r_{i}$ is more important than $r_{j}, \alpha=a_{i j}{ }^{M}-a_{i j}{ }^{L}$, $\beta=a_{i j}{ }^{R}-a_{i j}{ }^{M}$. In turn, when $r_{j}$ is more important than $r_{i}, \alpha=a_{j i}{ }^{M}-a_{j i}{ }^{L}, \beta=a_{j i}{ }^{R}-a_{j i}{ }^{M}$. the ambiguity is small when $0<\alpha, \beta<0.5$ which can not show good reflection of the ambiguity of people's understanding; when $\alpha, \beta>1$, the ambiguity is too large, and the confidence is reduced; when $0.5<\alpha, \beta<1$, the ambiguity is most suitable [21].

The fuzzy judgment matrix is transformed into a fuzzy complementary matrix using (3). The fuzzy judgment matrix mentioned in this paper is the fuzzy complementary matrix [22].

$$
\begin{aligned}
& r_{i j}=\left(\frac{1}{a_{j i}^{R}}, \frac{1}{a_{j i}^{M}}, \frac{1}{a_{j i}^{L}}\right) \\
& r_{j i}=\left(\frac{1}{a_{i j}^{R}}, \frac{1}{a_{i j}^{M}}, \frac{1}{a_{i j}^{L}}\right)
\end{aligned}
$$

$$
i, j=1,2, \ldots, m \text {. }
$$

3.2.3. Determining the Weight of Service Items. $r_{i j}$ represents the importance of the service item $S_{i}$ over the service item $S_{j}$ in the fuzzy matrix. $T_{j}$ denotes the comprehensive importance value of the $j$ th service item relative to other 
service items in the fuzzy judgment matrix. It can be obtained by the following formula:

$$
T_{j}=\sum_{i=1}^{m} r_{i j} \times \frac{1}{\sum_{j=1}^{m} \sum_{i=1}^{m} r_{i j}} \quad i, j=1,2, \ldots, m,
$$

where $T_{j}$ is a triangular fuzzy number $\left(a_{j}^{L}, a_{j}^{M}, a_{j}^{R}\right)$. Let $V\left(T_{j} \geq\right.$ $T_{k}$ ) indicate the degree of possibility of the triangular fuzzy number $T_{j} \geq T_{k} ; V\left(T \geq T_{1}, T_{2}, \ldots, T_{k}\right)$ is the degree of possibility that the triangular fuzzy number $T$ is greater than or equal to others triangular fuzzy numbers. $l_{j}$ indicates the measure of service item $S_{j}$ excellent for other service items, that is, the weight. It can be expressed as

$$
l_{j}=\left(T_{j} \geq T_{1}, \ldots, T_{j-1}, T_{j+1}, \ldots, T_{m}\right) .
$$

When $a_{k}^{M}<a_{j}^{M}$,

$$
V\left(T_{k} \geq T_{j}\right)= \begin{cases}\frac{a_{j}^{L}-a_{k}^{M}}{\left(a_{k}^{M}-a_{k}^{R}\right)-\left(a_{j}^{M}-a_{j}^{R}\right)}, & a_{j}^{L}>a_{k}^{R} \\ 0, & \text { others. }\end{cases}
$$

$$
\text { Or when } a_{k}^{M} \geq a_{j}^{M}
$$

$$
V\left(T_{k} \geq T_{j}\right)=1 .
$$

Note that $L=\left\{l_{1}, l_{2}, \ldots, l_{m}\right\}$ is a collection of the weight of service items, where $l_{j}$ denotes the weight of the $j$ th service items. According to (6) and (7) the absolute weight $l_{j}$ of the service item $S_{j}$ can be obtained. And, then, the absolute weight vector $L$ is normalized to obtain the relative weight vector $L^{*}=\left(l_{1}{ }^{*}, l_{2}{ }^{*}, \ldots, l_{m}{ }^{*}\right)$ of service items, where $l_{j}{ }^{*}$ represents the relative weight of the service item $S_{j}$. The relative weight vector $L^{*}$ can be calculated as

$$
l_{j}^{*}=\frac{l_{j}}{\sum_{j=1}^{m} l_{j}}, \quad j=1,2, \ldots, m .
$$

Obviously, $l_{j}{ }^{*}$ meets $\sum_{j=1}^{m} l_{j}{ }^{*}=1,0 \leq l_{j}^{*} \leq 1, j=$ $1,2, \ldots, m$.

\subsection{Customer Market Segmentation Based on Logit Model.} Different customers have different customer value and customer profit for the same enterprise. According to different customer value, classify customers to help enterprises identify valuable customers. Enterprises can concentrate on serving higher value customers, so as to improve their profitability and competitive advantage. The customer value denotes the size of the customer's net cash flow, the core of which is the contribution of cash flow [23]. The customer value includes the current value and the future value: the current value assumes that the customer's current purchase mode remains unchanged as well as the profit that the customer can create for the company in the future; the future value is assumed by adopting the appropriate marketing strategy to make the customer's purchase behavior develop toward the direction of increasing profits and the profit that the customer can create



FIGURE 5: Customer market segmentation.

for the company in the future [24]. Based on the difference of customer value, this paper uses the two indicators of customer total consumption and service expectation value to customer market segments, as shown in Figure 5. The two indicators of customer total consumption and service expectation value can not only express the current value of the customers, but also predict the potential value of the customers in the future. The method first predicts the customer total consumption in their life cycle according to the customer's historical transaction record and the customer's purchase intention. Then, according to the expected utility of different brands of the same product, we measure the next purchase probability of consumers and establish a Markov prediction model for each consumer. The customer is classified by predicting customer total consumption in the future period and service expectation value of customers.

Burden Customer. The customer total consumption and the service expectation value are very low so this kind of customers value is low. If the enterprise resources are limited, enterprises can ignore such customers.

Problem Customer. The most unattractive class of customers is that where the customer total consumption is very low but the service expectation value is very high. These customers are a burden on the company. It is not suitable for the company to invest any resources to maintain this kind of customers. It can be lost and may even take some marketing strategies to remove the relationship.

Loyal Customer. The most attractive class of customers is that where the customer total consumption is very high and the service expectation value is very low. For this kind of customers company should invest the appropriate resources to maintain the stability of the relationship between the two parties so that the customer will continue to be satisfied.

Gold Customer. The customer total consumption and the service expectation value are very high so this kind of customers value is high. The difference between this type of customer and the loyal customer is that the enterprise needs to invest more resources to meet the customer's higher service 
expectations. This kind of customers has a great impact on the company's profit, so the company maintains the stability of such customers by investing more resources.

3.3.1. Forecast of Customer Total Consumption. The customer total consumption is the sum of the net present values of the same product purchased in the life cycle of the customer. The greater the customer total consumption, the greater the customer need for the product. On the other hand, the smaller the customer total consumption, the smaller the customer need for the product.

Suppose the customer has the same amount of consumption each time and the two time intervals are equal. So the customer's total consumption $Q$ can be expressed as [25]

$$
Q=\sum_{t=0}^{T}(1+d)^{-t} V_{t},
$$

where $T$ is the expected number of customers consumption in the life cycle; $d$ is the discount rate; $V_{t}$ is $t$ th customer total consumption.

The expected number of customers consuming $T$ is the number of times that the customer buys this kind of service product in its life cycle, and it can be obtained by

$$
T=\left[\frac{n}{f}\right],
$$

where $n$ is the life cycle length of a customer; $f$ is the two time intervals. The impact of the customer's life cycle length involves a lot of factors, like corporate variables, customer variables, environmental variables, and many other factors. Because the social development environment changes too fast, the prediction of longer time consumption can not guarantee its accuracy and reliability, so the value of $n$ does not exceed 5 years.

3.3.2. Prediction of Service Expectation Value. The service expectation value is the customer satisfaction degree of the service quality. If the satisfaction degree of a customer is $100 \%$, it is meaningless to invest in resources to improve the customer's service expectations. The Logit model is used to predict service expectation value for different service elements.

Based on the theory of random utility in Logit model $[26,27]$, the service total utility is made up of two parts of the service random utility and the service random utility, as shown by

$$
w_{j}=v_{j}+e_{j}
$$

Let $W=\left[w_{1}, \ldots, w_{j}\right]$ denote service total utility of the service items, where $w_{j}$ denotes service total utility of the $j$ th service item, $j=1,2, \ldots, m . v_{j}$ is the service utility decision part of the $j$ th service items; $e_{j}$ is the service utility random part of the $j$ th service items.

In addition to taking into account the self-attributes of each service item, the utility of a service item should also take into account the customer selection inertia, that is, the behavior of the customer. In 1983, Guadagni and Little demonstrated that customer selection inertia in the selection model was a very important factor [25]. Therefore, the expected utility model can be expressed as

$$
w_{j p}^{\prime}=v_{j p}+e_{j p}+b_{o j} \text { Last }_{j p}
$$

where $w_{j p}^{\prime}$ is total utility of the $p$ th service item in the case of the last choice of the $j$ th service item; $b_{o j}$ is the inertia coefficient of goods purchased by regression analysis; if $j=k$, Last $_{i j k}=1$; else $j \neq k$, last $=0$.

Let $U_{j p}=b_{o j}$ Last $_{j p}+V_{j p}$, comprehensive equations (11) and (12), the probability of the customer selecting the $p$ th service item is expressed as

$$
p_{j p}=\frac{e^{U_{j p}}}{\sum_{p=1}^{k} e^{U_{j p}}} .
$$

The service decision utility $V$ is determined by the relevant variables of the service item, the relevant variables of the customer, and the other variables. It is assumed that the service decision utility is determined by the $N$ observable variables, and the service decision utility can be expressed as

$$
V_{i p}=\sum_{n=1}^{N} b_{n} x_{i p n}
$$

According to (13) and (14), when the customer selected the $j$ th service item last time, the probability of selecting the $p$ th service item can be expressed as

$$
p_{j p}=\frac{e^{b_{o j} \operatorname{Last}_{j p}+\sum_{n=1}^{N} b_{n} x_{p n}}}{\sum_{p=1}^{k} e^{b_{o j} \operatorname{Last}_{j p}+\sum_{n=1}^{N} b_{n} x_{p n}}},
$$

where $x_{k n}$ is the known value of the evaluation; $b_{n}(n=$ $0,1,2, \ldots, N)$ is the weight vector of the attribute. $p_{j p}$ denotes the case when the customer selected the $j$ th service item last time and the probability of selecting the $p$ th service item, $j=1,2, \ldots, m, p=1,2, \ldots, k$.

The selection probability of $t$ times to the $j$ th service item using Markov method:

$$
\begin{aligned}
& \left(B_{1 t}, B_{2 t}, \ldots, B_{j t}\right) \\
& =\left(A_{1}, A_{2}, \ldots, A_{j}\right)\left[\begin{array}{cccc}
P_{11} & P_{12} & \cdots & P_{1 k} \\
P_{21} & P_{22} & \cdots & P_{2 k} \\
& & \\
& & \\
P_{j 1} & P_{j 2} & \cdots & P_{j k}
\end{array}\right]^{t},
\end{aligned}
$$

where $B_{j t}$ denotes the selection probability of $t$ times to the $j$ th service item; $A_{j}$ denotes $t$ of selection probability of the $j$ th service item, according to the survey, $j=1,2, \ldots, m$.

The service expectation value $D$ can be expressed as

$$
D=\frac{\sum_{t=0}^{T}(1+d)^{-t} V B_{j t}}{Q} .
$$


3.4. Calculating Alternative Customer Satisfaction Level [28]. Using questionnaires to investigate customers who have experience with the service product to get customer expectations and customer perception for service elements, let $z_{d j}^{t}$ denote that the $d$ th customers give the customer expectation value $t$ for the $j$ th service items; $g_{d j}^{t}$ denotes that the $d$ th customers give the customer perception value $t$ for the $j$ th service items; the value of $t$ ranges from 1 to 10 , where " 1 " means the worst and "10" means the best. Setting 0-1 variable $\phi_{d j}^{t}$, when $z_{d j}^{t} \leq g_{d j}^{t}, \phi_{d j}^{t}=1$; else when $z_{d j}^{t}>g_{d j}^{t}, \phi_{d j}^{t}=0$, $d=1,2, \ldots, r, j=1,2, \ldots, m, t \in[1,10]$.

Let $o_{j}^{t}$ denote the number of customers who expect less than/equal to what is perceived, $0 \leq o_{j}^{t} \leq r, \sum_{t=1}^{10} o_{j}^{t}=r$. It can be calculated as

$$
o_{j}^{t}=\sum_{d=1}^{r} \phi_{d j}^{t}, \quad j=1,2, \ldots, m, t=1,2, \ldots, 10 .
$$

Then, according to (18), we can calculate the probability of service item $\left(S_{j}\right)$ that the customer expectation value is $t$. It can be calculated as

$$
p_{j}^{t}=\frac{o_{j}^{t}}{r}, \quad j=1,2, \ldots, m, t=1,2, \ldots, 10,
$$

where $0 \leq p_{j}^{t} \leq 1$ and $\sum_{t=1}^{10} p_{j}^{t}=1, j=1,2, \ldots, m$.

Let $F\left(Z_{j}\right)$ denote the customer expectation for service item $S_{j}$, which can be represented by

$$
F\left(Z_{j}\right)=\sum_{t=1}^{10} t p_{j}^{t}, \quad j=1,2, \ldots, m, t=1,2, \ldots, 10 .
$$

For the convenience of further analysis, we can calculate the comprehensive evaluation $\varphi_{j p}$ of the service scheme $H_{j p}$ of service item $S_{j}$. It is obtained by

$$
\varphi_{j p}=b_{j p} \eta_{j p}, \quad j=1,2, \ldots, m ; p=1,2, \ldots, k,
$$

where $b_{j p}$ denotes the customer's evaluation value for the service element $S_{j p} ; \eta_{j p}$ denotes the weight of the service element $S_{j p}$.

According to (20) and (21) to obtain the comprehensive evaluation $\varphi_{j p}$ and the customer group's expectation $F\left(Z_{j}\right)$, the customer satisfaction $\psi_{j p}$ for the service scheme $H_{j p}$ of service item $S_{j}$ is expressed by

$$
\begin{aligned}
& \psi_{j p} \\
& = \begin{cases}1, & \varphi_{j p}=\varphi_{j p}^{\max } \geq F\left(Z_{j}\right) \\
\varepsilon+(1-\varepsilon) \frac{\varphi_{j p}-F\left(Z_{j}\right)}{\varphi_{j p}^{\max }-F\left(Z_{j}\right)}, & F\left(Z_{j}\right) \leq \varphi_{j p}<\varphi_{j p}^{\max } \\
0, & \varphi_{j p}<F\left(Z_{j}\right),\end{cases}
\end{aligned}
$$

where $\varphi_{j p}^{\max }=\max \left\{\varphi_{j 1}, \varphi_{j 2}, \ldots, \varphi_{j m}\right\} ; \varepsilon$ is the satisfaction threshold given by the decision maker.

It can be seen from (22) that the comprehensive evaluation $\varphi_{j p}$ of the service scheme $H_{j p}$ does not satisfy the customer expectation on the service element $S_{j p}$; the customer satisfaction $\psi_{j p}$ of the service scheme $H_{j p}$ is zero; that is, $\psi_{j p}=0$; customer satisfaction is $\varepsilon$ when it just meets the customer group's expectation on service items; the comprehensive evaluation $\varphi_{j p}$ is equal to the customer expectation, $\psi_{j p}=\varepsilon$. If the comprehensive evaluation $\varphi_{j p}$ is increasing, it will be greater than the customer expectation, and the customer satisfaction $\psi_{j p}$ is greater.

3.5. Service Elements Optimization Configuration Model. To maximize customer satisfaction is the ultimate goal of service-oriented enterprises. In this paper, customer satisfaction maximization is the goal, considering the conditions of business costs are limited and then establishing service factor optimization model:

$$
\begin{array}{ll}
\max & Z=\sum_{t=1}^{4} G_{t}\left[\sum_{j=1}^{m} l_{j}\left(\sum_{p=1}^{k} \varphi_{j p} x_{j p}\right)\right] \\
\text { s.t. } & \sum_{j=1}^{m} \sum_{p=1}^{k} c_{j p} x_{j p}<C \\
& \sum_{p=1}^{k} x_{j p}=1 \\
& x_{j p}=0 ; 1, j=1,2, \ldots, m, p=1,2, \ldots, k,
\end{array}
$$

where $G_{t}$ denotes the $t$ th customer market share; $x_{j p}=0$ denotes that $H_{j p}$ is not selected; on the contrary, $x_{j p}=1$ denotes that $H_{j p}$ is selected.

Here, (23) is the max customer satisfaction of service product quality; (23a) is the total cost of the service elements that are selected which can not exceed the expected total cost; (23b) indicates that only one service element is selected for each service item.

\section{Illustrative Example}

4.1. Problem Description. In recent years, China's traffic transportation industry has shown a steady, long-lasting, and rapid development trend. The steady increase has led the railway transportation industry to show a fierce competitive trend, the key to the development and performance improvement of the railway transportation industry in their service quality. SC Railway Bureau is going to invest 70 million yuan to improve its service quality of high-end cabin between A city and C city.

Take the high-iron service as an example to improve the service of the first class of high-speed rail to verify the effectiveness and feasibility of the model. References [11, 29, 30] involved the railway transportation industry service quality evaluation program and then conducted a questionnaire survey for 350 passengers having high-end experience of this route. According to the statistical analysis, Delphi method is used to obtain four customer needs: high-quality cabin service $\left(\mathrm{CR}_{1}\right)$; high-quality food service $\left(\mathrm{CR}_{2}\right)$; recreational satisfaction $\left(\mathrm{CR}_{3}\right)$; and clean and tidy environment $\left(\mathrm{CR}_{4}\right): 6$ service items and 14 service elements as shown in Figure 6. 




Figure 6: AHP model of high-iron service.

4.2. Establishment of Optimization Model. Choose three experts to evaluate the service items to get fuzzy judgment matrix, as shown in Table 2. And then the evaluation of three experts to find the average is found in Table 3.

According to (2)-(4), we can get the comprehensive importance of the service items.

$$
\begin{aligned}
T_{1}= & (3.333,4.300,4.967) \\
& \times\left(\frac{1}{73.909}, \frac{1}{47.193}, \frac{1}{35.304}\right) \\
= & (0.045,0.091,0.141) \\
T_{2}= & (4.188,5.189,6.578) \\
& \times\left(\frac{1}{73.909}, \frac{1}{47.193}, \frac{1}{35.304}\right) \\
= & (0.057,0.110,0.186) \\
T_{3}= & (4.334,5.532,7.400) \\
& \times\left(\frac{1}{73.909}, \frac{1}{47.193}, \frac{1}{35.304}\right)
\end{aligned}
$$

$=(0.059,0.117,0.210)$

$T_{4}=(5.382,6.593,8.667)$

$\times\left(\frac{1}{73.909}, \frac{1}{47.193}, \frac{1}{35.304}\right)$

$=(0.073,0.140,0.245)$

$T_{5}=(7.035,8.412,10.854)$

$\times\left(\frac{1}{73.909}, \frac{1}{47.193}, \frac{1}{35.304}\right)$

$=(0.095,0.178,0.307)$

$T_{6}=(11.032,17.166,35.444)$

$\times\left(\frac{1}{73.909}, \frac{1}{47.193}, \frac{1}{35.304}\right)$

$=(0.149,0.364,1.004)$. 
TABLE 2: Fuzzy judgment matrix of service items.

\begin{tabular}{|c|c|c|c|c|c|c|}
\hline \multirow{2}{*}{ Fuzzy judgment matrix } & \multicolumn{6}{|c|}{ Service items } \\
\hline & $S_{1}$ & $S_{2}$ & $S_{3}$ & $S_{4}$ & $S_{5}$ & $S_{6}$ \\
\hline \multirow{3}{*}{$S_{1}$} & $(1,1,1)$ & $(2 / 5,1 / 2,3 / 5)$ & $(2 / 5,7 / 10,4 / 5)$ & $(1 / 2,7 / 10,4 / 5)$ & $(3 / 5,4 / 5,9 / 10)$ & $(2 / 5,1 / 2,4 / 5)$ \\
\hline & $(1,1,1)$ & $(3 / 10,1 / 2,3 / 5)$ & $(1 / 2,4 / 5,9 / 10)$ & $(3 / 5,7 / 10,9 / 10)$ & $(1 / 2,7 / 10,9 / 10)$ & $(2 / 5,1 / 2,4 / 5)$ \\
\hline & $(1,1,1)$ & $(2 / 5,3 / 5,7 / 10)$ & $(3 / 5,4 / 5,9 / 10)$ & $(1 / 2,7 / 10,4 / 5)$ & $(3 / 5,7 / 10,4 / 5)$ & $(3 / 10,1 / 2,7 / 10)$ \\
\hline \multirow{3}{*}{$S_{2}$} & $(5 / 3,2,5 / 2)$ & $(1,1,1)$ & $(2 / 5,1 / 2,7 / 10)$ & $(1 / 2,3 / 5,4 / 5)$ & $(1 / 2,7 / 10,4 / 5)$ & $(1 / 10,1 / 5,1 / 2)$ \\
\hline & $(5 / 3,2,10 / 3)$ & $(1,1,1)$ & $(3 / 10,3 / 5,4 / 5)$ & $(1 / 2,7 / 10,4 / 5)$ & $(3 / 5,4 / 5,9 / 10)$ & $(1 / 10,2 / 5,1 / 2)$ \\
\hline & $(10 / 7,5 / 3,5 / 2)$ & $(1,1,1)$ & $(2 / 5,1 / 2,4 / 5)$ & $(1 / 2,7 / 10,9 / 10)$ & $(7 / 10,4 / 5,9 / 10)$ & $(1 / 5,2 / 5,3 / 5)$ \\
\hline \multirow{3}{*}{$S_{3}$} & $(5 / 4,10 / 7,2)$ & $(10 / 7,2,5 / 2)$ & $(1,1,1)$ & $(2 / 5,1 / 2,3 / 5)$ & $(2 / 5,1 / 2,3 / 5)$ & $(1 / 10,1 / 5,2 / 5)$ \\
\hline & $(10 / 9,5 / 4,2)$ & $(5 / 4,5 / 3,10 / 3)$ & $(1,1,1)$ & $(3 / 10,1 / 2,7 / 10)$ & $(3 / 10,1 / 2,7 / 10)$ & $(1 / 5,2 / 5,1 / 2)$ \\
\hline & $(10 / 9,5 / 4,5 / 3)$ & $(5 / 4,2,5 / 2)$ & $(1,1,1)$ & $(2 / 5,3 / 5,7 / 10)$ & $(3 / 10,2 / 5,1 / 2)$ & $(1 / 5,2 / 5,1 / 2)$ \\
\hline \multirow{3}{*}{$S_{4}$} & $(5 / 4,10 / 7,2)$ & $(5 / 4,5 / 3,2)$ & $(5 / 3,2,5 / 2)$ & $(1,1,1)$ & $(2 / 5,1 / 2,3 / 5)$ & $(1 / 10,3 / 10,2 / 5)$ \\
\hline & $(10 / 9,10 / 7,5 / 3)$ & $(5 / 4,10 / 7,2)$ & $(10 / 7,2,10 / 3)$ & $(1,1,1)$ & $(3 / 10,2 / 5,1 / 2)$ & $(1 / 10,3 / 10,2 / 5)$ \\
\hline & $(5 / 4,10 / 7,2)$ & $(10 / 9,10 / 7,2)$ & $(10 / 7,5 / 3,5 / 2)$ & $(1,1,1)$ & $(3 / 10,2 / 5,1 / 2)$ & $(1 / 5,2 / 5,1 / 2)$ \\
\hline \multirow{3}{*}{$S_{5}$} & $(10 / 9,5 / 4,5 / 3)$ & $(5 / 4,10 / 7,2)$ & $(5 / 3,2,5 / 2)$ & $(5 / 3,2,5 / 2)$ & $(1,1,1)$ & $(1 / 10,1 / 5,2 / 5)$ \\
\hline & $(10 / 9,10 / 7,2)$ & $(10 / 9,5 / 4,5 / 3)$ & $(10 / 7,2,10 / 3)$ & $(2,5 / 2,10 / 3)$ & $(1,1,1)$ & $(1 / 10,1 / 5,2 / 5)$ \\
\hline & $(5 / 4,10 / 7,5 / 3)$ & $(10 / 9,5 / 4,10 / 7)$ & $(2,5 / 2,10 / 3)$ & $(2,5 / 2,10 / 3)$ & $(1,1,1)$ & $(1 / 5,3 / 10,1 / 2)$ \\
\hline \multirow{3}{*}{$S_{6}$} & $(5 / 4,2,5 / 2)$ & $(2,5,10)$ & $(5 / 2,5,10)$ & $(5 / 2,10 / 3,10)$ & $(5 / 2,5,10)$ & $(1,1,1)$ \\
\hline & $(5 / 4,2,5 / 2)$ & $(2,5 / 2,10)$ & $(2,5 / 2,5)$ & $(5 / 2,10 / 3,10)$ & $(5 / 2,5,10)$ & $(1,1,1)$ \\
\hline & $(10 / 7,2,10 / 3)$ & $(5 / 3,5 / 2,5)$ & $(2,5 / 2,5)$ & $(2,5 / 2,5)$ & $(2,10 / 3,5)$ & $(1,1,1)$ \\
\hline
\end{tabular}

The absolute weight vector of each service item is obtained using (5) and (6):

$$
\begin{aligned}
l_{1} & =\left(T_{1} \gg T_{2}, \ldots, T_{6}\right) \\
& =\min (0.152,0.147,0.120,0.077,0.28)=0.077, \\
l_{2} & =\left(T_{2} \gg T_{1}, \ldots, T_{6}\right) \\
& =\min (1,0.946,0.792,0.572,0.127)=0.127, \\
l_{3} & =\left(T_{3} \gg T_{1}, \ldots, T_{6}\right) \\
& =\min (1,1,0.395,0.353,0.224)=0.224, \\
l_{4} & =\left(T_{4} \gg T_{1}, \ldots, T_{6}\right)=\min (1,1,1,0.478,0.216) \\
& =0.216, \\
l_{5} & =\left(T_{5} \gg T_{1}, \ldots, T_{6}\right)=\min (1,1,1,1,0.475) \\
& =0.475, \\
l_{6} & =\left(T_{6} \gg T_{1}, \ldots, T_{5}\right)=\min (1,1,1,1,1)=1 .
\end{aligned}
$$

Then, the relative weight vector of each service item is obtained using (8).

$$
l_{j}^{*}=(0.036,0.060,0.106,0.102,0.224,0.427)
$$

Let customers use the scoring method of " $1-5$ " to score the decisive utility and random utility of the service items, and then average the collected data to obtain the utility of each service element, as shown in Table 4.
According to (12)-(15), the probability of selecting the $p$ th service item in the case that customer chooses the $j$ th service item at the last time is calculated as shown in Table 5.

Using score of " $0-10$," we get the customer satisfaction of the service quality in one high-speed rail travel. According to (9) and (10), we calculate the customer total consumption of the service items in their life cycle; that is, $Q=18.397$.

According to the literature analysis [31,32], we can choose 3 years of the customer life cycle and the discount rate of satisfaction is 0.002 .

It can be seen that the service team concluded that the probability of the customer's last choice of the service items was $A_{j}=(0.3,0.1,0.2,0.1,0.1,0.2)$, according to the questionnaire survey. And then we can obtain the $j$ th service item which is selected for $t$ times using (16).

$$
\begin{aligned}
& B_{15}=0.17, \\
& B_{25}=0.167, \\
& B_{35}=0.167, \\
& B_{45}=0.165, \\
& B_{55}=0.165, \\
& B_{65}=0.166 .
\end{aligned}
$$

Combine (16) and (17) to calculate the expected utility of the service items: $S_{1}=0.193, S_{2}=0.153, S_{3}=0.162, S_{4}=$ $1.153, S_{5}=1.169, S_{6}=0.161$.

The total value of $y$-axis $Q$ is 18.397 and the total value of $x$-axis is 1.7. The customer group can be divided into four 





TABLE 4: Service utility table.

\begin{tabular}{|c|c|c|c|c|c|c|}
\hline Service items & Index system & Index weight & $\begin{array}{c}\text { Decided } \\
\text { utility }\left(v_{i j}\right)\end{array}$ & $\begin{array}{l}\text { Random } \\
\text { utility }\left(e_{i j}\right)\end{array}$ & Utility $\left(w_{i j}\right)$ & $\begin{array}{c}\text { Inertia } \\
\text { coefficient } \\
\left(b_{o i}\right)\end{array}$ \\
\hline$S_{1}$ : service staff factor & $\{$ fashionable, stylization, timeliness $\}$ & $\{0.4,0.4,0.2\}$ & $\{4,4,5\}$ & $\{4,4,2\}$ & 7.8 & 0.3 \\
\hline$S_{2}:$ catering service factor & $\{$ Fashionable, stylization, diversity $\}$ & $\{0.2,0.4,0.4\}$ & $\{3,3,4\}$ & $\{3,4,1\}$ & 6 & 0.2 \\
\hline$S_{3}$ : beverage service factor & $\{$ Fashionable, stylization, diversity $\}$ & $\{0.2,0.3,0.5\}$ & $\{2,4,4\}$ & $\{3,4,1\}$ & 5.9 & 0.2 \\
\hline$S_{4}$ : leisure reading factor & $\{$ Fashionable, cleanliness, diversity $\}$ & $\{0.2,0.4,0.4\}$ & $\{3,3,4\}$ & $\{3,2,1\}$ & 5.2 & 0.1 \\
\hline$S_{5}$ : entertainment factors & $\{$ Fashionable, clarity, cleanliness\} & $\{0.1,0.5,0.4\}$ & $\{4,4,4\}$ & $\{1,2,1\}$ & 5.5 & 0.1 \\
\hline$S_{6}$ : cabin cleaning factor & $\{$ timeliness, cleanliness, consistency\} & $\{0.4,0.2,0.4\}$ & $\{4,4,3\}$ & $\{2,1,3\}$ & 5.8 & 0.1 \\
\hline
\end{tabular}

TABLE 5: Utility-probability value table.

\begin{tabular}{|c|c|c|c|c|c|c|}
\hline & $S_{1}$ & $S_{2}$ & $S_{3}$ & $S_{4}$ & $S_{5}$ & $S_{6}$ \\
\hline \multirow{6}{*}{$u_{j p}$} & $u_{11}=4.5$ & $u_{21}=4.2$ & $u_{31}=4.2$ & $u_{41}=4.2$ & $u_{51}=4.2$ & $u_{61}=4.2$ \\
\hline & $u_{12}=3.4$ & $u_{22}=3.6$ & $u_{32}=3.4$ & $u_{42}=3.4$ & $u_{52}=3.4$ & $u_{62}=3.4$ \\
\hline & $u_{13}=3.6$ & $u_{23}=3.6$ & $u_{33}=3.8$ & $u_{43}=3.6$ & $u_{53}=3.6$ & $u_{63}=3.6$ \\
\hline & $u_{14}=3.4$ & $u_{24}=3.4$ & $u_{34}=3.4$ & $u_{44}=3.5$ & $u_{54}=3.4$ & $u_{64}=3.4$ \\
\hline & $u_{15}=4$ & $u_{25}=4$ & $u_{35}=4$ & $u_{45}=4$ & $u_{55}=4.1$ & $u_{65}=4$ \\
\hline & $u_{16}=3.6$ & $u_{26}=3.6$ & $u_{36}=3.6$ & $u_{46}=3.6$ & $u_{56}=3.6$ & $u_{66}=3.7$ \\
\hline \multirow{6}{*}{$p_{j p}$} & $p_{11}=0.217$ & $p_{21}=0.164$ & $p_{31}=0.164$ & $p_{41}=0.167$ & $p_{51}=0.159$ & $p_{61}=0.167$ \\
\hline & $p_{12}=0.155$ & $p_{22}=0.194$ & $p_{32}=0.159$ & $p_{42}=0.162$ & $p_{52}=0.158$ & $p_{62}=0.162$ \\
\hline & $p_{13}=0.157$ & $p_{23}=0.160$ & $p_{33}=0.195$ & $p_{43}=0.163$ & $p_{53}=0.158$ & $p_{63}=0.163$ \\
\hline & $p_{14}=0.155$ & $p_{24}=0.159$ & $p_{34}=0.159$ & $p_{44}=0.179$ & $p_{54}=0.159$ & $p_{64}=0.162$ \\
\hline & $p_{15}=0.159$ & $p_{25}=0.163$ & $p_{35}=0.163$ & $p_{45}=0.166$ & $p_{55}=0.208$ & $p_{65}=0.166$ \\
\hline & $p_{16}=0.157$ & $p_{26}=0.160$ & $p_{36}=0.160$ & $p_{46}=0.163$ & $p_{56}=0.158$ & $p_{66}=0.180$ \\
\hline
\end{tabular}

\begin{tabular}{c|c|c|c|}
\cline { 2 - 3 } \begin{tabular}{c|c|} 
Customer \\
total \\
$\begin{array}{c}\text { consumption } \\
(Q)\end{array}$
\end{tabular} & High & $\begin{array}{c}\text { Loyal customer } \\
\left(G_{3}=0.305\right)\end{array}$ & $\begin{array}{c}\text { Gold customer } \\
\left(G_{4}=0.223\right)\end{array}$ \\
\cline { 2 - 4 } & Low & $\begin{array}{c}\text { Burden customer } \\
\left(G_{1}=0.311\right)\end{array}$ & $\begin{array}{c}\text { Problem customer } \\
\left(G_{2}=0.161\right)\end{array}$ \\
\cline { 2 - 3 } & \multicolumn{2}{|c|}{ Low } & High \\
\cline { 2 - 3 } & \multicolumn{2}{|c|}{ Service expectation value $(D)$}
\end{tabular}

FIGURE 7: Customer market segmentation.

quadrants according to the value of the $y$-axis and $x$-axis coordinates as shown in Figure 7.

According to the questionnaire survey, adopting the scoring principle of " $1-10$," we get to adopt the scoring principle of "1-10" and establish the expected probability distribution of the service items based on (18) and (19), as shown in Table 6.

According to (20) and Table 5, we can be obtain customer service expectations of the service items: $F\left(Z_{1}\right)=4.1$, $F\left(Z_{2}\right)=6.7, F\left(Z_{3}\right)=7.5, F\left(Z_{4}\right)=3.85, F\left(Z_{5}\right)=5.05$, $F\left(Z_{6}\right)=7.95$.
According to the questionnaire survey, we can obtain the index system and index weight of the service items giving the service schemes, as shown in Table 7.

Delphi method was used to get the evaluation matrix $A_{j}$ of the service schemes $H_{j m}$ for the service items $S_{j}$.

$$
\begin{aligned}
& A_{1}=\left[\begin{array}{lll}
6 & 6 & 8 \\
8 & 7 & 6
\end{array}\right] \\
& A_{2}=\left[\begin{array}{lll}
9 & 9 & 5 \\
8 & 7 & 6 \\
3 & 2 & 1
\end{array}\right] \\
& A_{3}=\left[\begin{array}{lll}
6 & 6 & 8 \\
4 & 3 & 1
\end{array}\right] \\
& A_{4}=\left[\begin{array}{lll}
6 & 6 & 8 \\
5 & 5 & 4
\end{array}\right] \\
& A_{5}=\left[\begin{array}{lll}
6 & 7 & 5 \\
5 & 3 & 4 \\
4 & 5 & 6
\end{array}\right] \\
& A_{6}=\left[\begin{array}{lll}
3 & 4 & 8 \\
9 & 8 & 7
\end{array}\right] .
\end{aligned}
$$


TABLE 6: Expected probability distribution of service items.

\begin{tabular}{lcccccccccc}
\hline Service items & 1 & 2 & 3 & 4 & 5 & 6 & 7 & 8 & 9 \\
\hline$S_{1}$ & 0 & 0.25 & 0.3 & 0.2 & 0.1 & 0.1 & 0 & 0.05 & 0 & 0 \\
$S_{2}$ & 0 & 0 & 0.05 & 0 & 0.15 & 0.2 & 0.3 & 0.25 & 0 & 0.05 \\
$S_{3}$ & 0 & 0 & 0 & 0 & 0.05 & 0.2 & 0.3 & 0.2 & 0.15 & 0.1 \\
$S_{4}$ & 0.1 & 0.15 & 0.15 & 0.3 & 0.15 & 0.1 & 0 & 0 & 0.05 & 0 \\
$S_{5}$ & 0 & 0 & 0.2 & 0.25 & 0.05 & 0.3 & 0.05 & 0.1 & 0.05 & 0 \\
$S_{6}$ & 0 & 0 & 0 & 0 & 0 & 0.05 & 0.35 & 0.3 & 0.2 & 0.1 \\
\hline
\end{tabular}

TABLE 7: Description of cabin services and schemes.

\begin{tabular}{|c|c|c|c|}
\hline Service items & Index system & Index weight & Service schemes \\
\hline$S_{1}$ : service staff factor & $\{$ Fashionable, stylization, timeliness\} & $\{0.4,0.4,0.2\}$ & $\begin{array}{c}H_{11}: \text { ordinary flight attendants } \\
H_{12}: \text { star flight attendants }\end{array}$ \\
\hline$S_{2}$ : catering service factor & $\{$ Fashionable, stylization, diversity $\}$ & $\{0.2,0.4,0.4\}$ & $\begin{array}{c}H_{21}: \text { scheme's two types of local specialties } \\
H_{22}: \text { scheme's two packages } \\
H_{23}: \text { a kind of course }\end{array}$ \\
\hline$S_{3}:$ beverage service factor & $\{$ Fashionable, stylization, diversity $\}$ & $\{0.2,0.3,0.5\}$ & $\begin{array}{l}H_{31}: \text { more types of drinks } \\
H_{32}: \text { type of single drink }\end{array}$ \\
\hline$S_{4}:$ leisure reading factor & $\{$ Fashionable, cleanliness, diversity $\}$ & $\{0.2,0.4,0.4\}$ & $\begin{array}{c}H_{41}: \text { providing magazines } \\
H_{42}: \text { offering a variety of newspapers }\end{array}$ \\
\hline$S_{5}:$ entertainment factors & $\{$ Fashionable, clarity, cleanliness\} & $\{0.1,0.5,0.4\}$ & $\begin{array}{c}H_{51} \text { : equipped with small entertainment TV } \\
H_{52} \text { : equipped with music player } \\
H_{53} \text { : equipped with small game consoles }\end{array}$ \\
\hline$S_{6}$ : cabin cleaning factor & $\{$ Timeliness, cleanliness, consistency\} & $\{0.4,0.2,0.4\}$ & $\begin{array}{c}H_{61}: \text { regularly cleaned } 3 \text { times } \\
H_{62}: \text { clean at any time }\end{array}$ \\
\hline
\end{tabular}

According to (21), the comprehensive evaluation value of each service scheme is expressed as follows: $\varphi_{11}=6.4, \varphi_{12}=$ $7.2, \varphi_{21}=7.4, \varphi_{22}=6.8, \varphi_{23}=1.8, \varphi_{31}=8, \varphi_{32}=2.2$, $\varphi_{41}=6.8, \varphi_{42}=4.6, \varphi_{51}=6.1, \varphi_{52}=3.6, \varphi_{53}=5.3, \varphi_{61}=5.2$, $\varphi_{62}=8$.

It is assumed that the satisfaction threshold of the service scheme is 0.4 ; that is, $\varepsilon=0.4$. Calculating the customer satisfaction of the service schemes is as follows: $\psi_{11}=0.85$, $\psi_{12}=1, \psi_{21}=1, \psi_{22}=0.48, \psi_{23}=0, \psi_{31}=1, \psi_{32}=0$, $\psi_{41}=1, \psi_{42}=0.57, \psi_{51}=1, \psi_{52}=0.54, \psi_{53}=0, \psi_{61}=0$, $\psi_{62}=1$.

The related variables of the service quality evaluation are summed up, as shown in Table 8.

According to (23), the service quality evaluation model can be established for the high-speed rail, as shown below.

$$
\begin{aligned}
& \max Z \\
&= 0.311\left(0.031 x_{11}+0.036 x_{12}+\cdots+0.427 x_{62}\right) \\
&+\cdots \\
&+0.223\left(0.031 x_{11}+0.036 x_{12}+\cdots+0.427 x_{62}\right) \\
& \text { s.t } \quad 300 x_{11}+1300 x_{12}+2500 x_{21}+2300 x_{22}+1200 x_{23} \\
&+\cdots+260 x_{62} \leq 7000 \\
& x_{11}+x_{12}=1 \\
& x_{21}+x_{22}+x_{23}=1
\end{aligned}
$$

$$
\begin{aligned}
& x_{31}+x_{32}=1 \\
& x_{41}+x_{42}=1 \\
& x_{51}+x_{52}+x_{53}=1 \\
& x_{61}+x_{62}=1 \\
& x_{j p}=1,0 .
\end{aligned}
$$

Using the Lingo software package to solve the model the optimal solution can be obtained: $x_{12}=1, x_{21}=1, x_{31}=1$, $x_{41}=1, x_{51}=1, x_{62}=1$, as shown in Figure 8 .

\section{Conclusions}

This paper presents a service quality evaluation model considering enterprise resource constraints and customer fuzzy evaluation information. Through the questionnaire survey and interviews to obtain customer needs for highspeed rail services and then through the expert group Delphi method obtains FHAHP model including 6 service items and 14 service elements. We use the triangular fuzzy hierarchy method to calculate the weight vector of the service items at the first. Secondly, we use the Logit model for customer market segmentation. And then we can forecast the customer's satisfaction with the service schemes. Finally, an evaluation model is set up with the goal of maximizing customer satisfaction. 
TABLE 8: Summary of factors related to service elements.

\begin{tabular}{|c|c|c|c|c|c|c|}
\hline$S_{j}$ & $l_{j}^{*}$ & $S_{j p}$ & $\varphi_{j p}$ & $\psi_{j p}$ & $H_{j p}$ & $c_{j p}$ (unit: wan) \\
\hline \multirow{2}{*}{$S_{1}$} & \multirow{2}{*}{0.036} & $S_{11}$ & 6.4 & 0.85 & $H_{11}$ & 300 \\
\hline & & $S_{12}$ & 7.2 & 1 & $H_{12}$ & 1300 \\
\hline \multirow{3}{*}{$S_{2}$} & \multirow{3}{*}{0.060} & $S_{21}$ & 7.4 & 1 & $H_{21}$ & 2500 \\
\hline & & $S_{22}$ & 6.8 & 0.48 & $H_{22}$ & 2300 \\
\hline & & $S_{23}$ & 1.8 & 0 & $H_{23}$ & 1200 \\
\hline \multirow{2}{*}{$S_{3}$} & \multirow{2}{*}{0.106} & $S_{31}$ & 8 & 1 & $H_{31}$ & 1300 \\
\hline & & $S_{32}$ & 2.2 & 0 & $H_{32}$ & 300 \\
\hline \multirow{2}{*}{$S_{4}$} & \multirow{2}{*}{0.102} & $S_{41}$ & 6.8 & 1 & $H_{41}$ & 500 \\
\hline & & $S_{42}$ & 4.6 & 0.57 & $H_{42}$ & 400 \\
\hline \multirow{3}{*}{$S_{5}$} & \multirow{3}{*}{0.224} & $S_{51}$ & 6.1 & 1 & $H_{51}$ & 300 \\
\hline & & $S_{52}$ & 3.6 & 0.54 & $H_{52}$ & 200 \\
\hline & & $S_{53}$ & 5.3 & 0 & $H_{53}$ & 250 \\
\hline \multirow{2}{*}{$S_{6}$} & \multirow{2}{*}{0.427} & $S_{61}$ & 5.2 & 0 & $H_{61}$ & 120 \\
\hline & & $S_{62}$ & 8 & 1 & $H_{62}$ & 260 \\
\hline
\end{tabular}

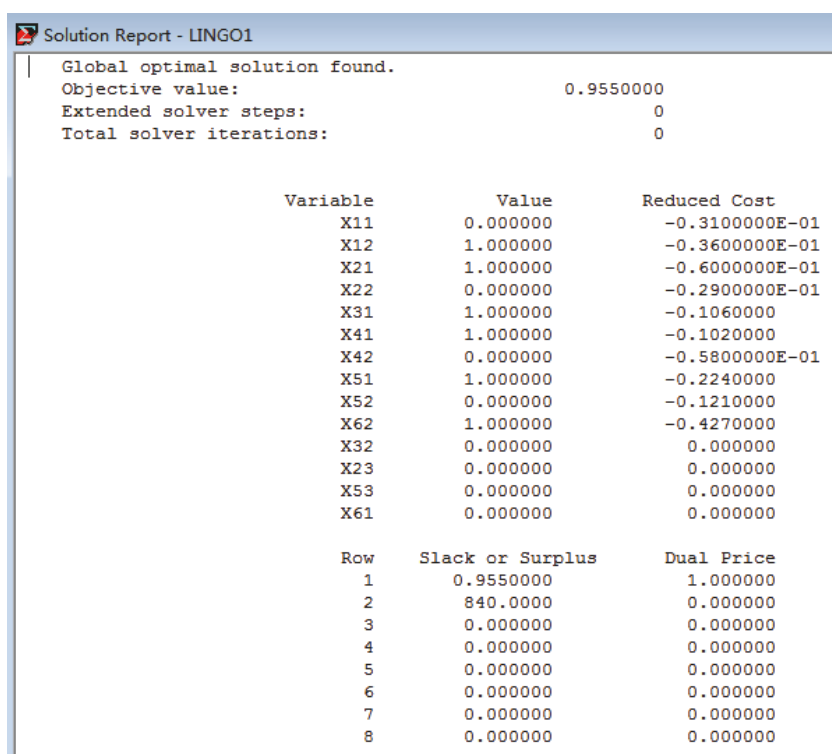

FIGURE 8: The service items selection diagram of Lingo.

In contrast to existing service product configuration models, this paper takes fully into account the ambiguity of customer satisfaction for service and the customer market segmentation, maximizing the customer's satisfaction. The method presented in this paper has the characteristics of clear and easy operation and has potential application value. It provides a new analytical model for rational and effective service quality evaluation under fuzzy environment.

\section{Discussion}

In this paper, we evaluate the service quality allocation scheme and introduce fuzzy numbers to ensure the completeness of evaluation information and the correctness of evaluation results. The initial model takes into account the incompatibility of service elements, but some service items including some service elements are compatible in real life. Taking the service quality evaluation of the high-speed rail high-end cabin in this paper as an example, the service items $S_{4}$ (leisure reading factors) and $S_{5}$ (entertainment factors) contain the compatibility of the service elements, so the service items $S_{4}$ (leisure reading factors) and $S_{5}$ (entertainment factors) can provide 2 service elements to participate in the configuration of the service scheme. In addition, the service elements contained in the rest of the service items $S_{1}$ (service staff factors), $S_{2}$ (catering service factors), $S_{3}$ (beverage service factors), and $S_{6}$ (cabin cleaning factors) are not compatible. With the goal of maximizing service customer satisfaction, considering the enterprise cost constraint and the compatibility of service elements, a new evaluation model is established, as shown below.

$$
\begin{array}{ll}
\max Z & \\
= & 0.311\left(0.031 x_{11}+0.036 x_{12}+\cdots+0.427 x_{62}\right) \\
& +\cdots \\
& +0.223\left(0.031 x_{11}+0.036 x_{12}+\cdots+0.427 x_{62}\right) \\
\text { s.t } \quad 300 x_{11}+1300 x_{12}+2500 x_{21}+2300 x_{22}+1200 x_{23} \\
& +\cdots+260 x_{62} \leq 7000 \\
& x_{11}+x_{12}=1 \\
x_{21} & +x_{22}+x_{23}=1 \\
x_{31} & +x_{32}=1 \\
1 \leq & x_{41}+x_{42} \leq 2 \\
1 \leq & x_{51}+x_{52}+x_{53} \leq 2 \\
x_{61} & +x_{62}=1 \\
x_{j p} & =1,0 .
\end{array}
$$




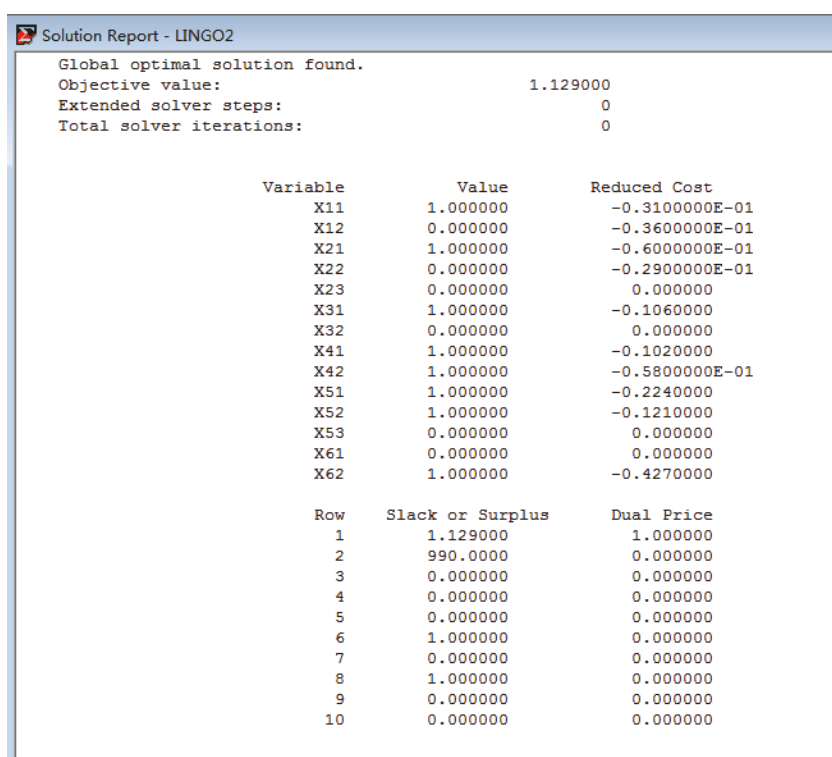

FIGURE 9: The service items selection diagram of Lingo.

Using the Lingo software package to solve the model the optimal solution can be obtained: $x_{11}=1, x_{21}=1, x_{31}=1$, $x_{41}=1, x_{42}=1, x_{51}=1, x_{52}=1, x_{62}=1$, as shown in Figure 9.

As shown in the picture, the new customer satisfaction is 1.129 relative to the old customer satisfaction value 0.955 , where the customer satisfaction is increased by 0.174 .

Because of the limited text, the competitor's factors are not taken into consideration when evaluating the service quality. Future research will be concentrated on the impact of competitor factors on the evaluation of the quality of service and the compatibility of service elements.

\section{Conflicts of Interest}

The authors declare that they have no conflicts of interest.

\section{Acknowledgments}

This work was financially supported by the Humanities and Social Sciences Planning Fund of the Ministry of Education (Grant no. 16YJC630085) in China and the Liaoning Province Department of Education Projects WGD2016018, WGD2016020, and WGD2016002. The authors wish to acknowledge the contribution of Liaoning Key Lab of Equipment Manufacturing Engineering Management, Liaoning Research Base of Equipment Manufacturing Development, Liaoning Key Research Base of Humanities and Social Sciences, Research Center of Micromanagement Theory, and Shenyang University of Technology.

\section{References}

[1] A. George and G. S. G. Kumar, "Impact of service quality dimensions in internet banking on customer satisfaction," Decision, vol. 41, no. 3, pp. 73-85, 2014.
[2] H. H. Wu and S. M. Hsieh, "A case study of applying importance-performance analysis in orthopedic department to evaluate service quality," International Journal of Management \& Decision Making, vol. 12, no. 1, pp. 50-68, 2017.

[3] J. Hallikas, M. Immonen, M. Pynnönen, and K. Mikkonen, "Service purchasing and value creation: Towards systemic purchases," International Journal of Production Economics, vol. 147, pp. 53-61, 2014.

[4] M. M. H. Chowdhury and M. A. Quaddus, "A multi-phased QFD based optimization approach to sustainable service design," International Journal of Production Economics, vol. 171, pp. 165-178, 2016.

[5] J. J. Cronin Jr. and S. A. Taylor, "Measuring service quality: a reexamination and extension," Journal of Marketing, vol. 56, no. 3, pp. 55-68, 1992.

[6] A. Parasuraman, V. A. Zeithaml, and L. L. Berry, "A Conceptual Model of Service Quality and Its Implications for Future Research," Journal of Marketing, vol. 49, no. 43, pp. 41-50, 1985.

[7] R. Liu, L. Cui, G. Zeng, H. Wu, and C. Wang, "Applying the fuzzy SERVQUAL method to measure the service quality in certification \& inspection industry," Applied Soft Computing, vol. 26, pp. 508-512, 2014.

[8] A. Caruana and L. F. Pitt, "Excellence, Market Orientation, Some Aspects of Service Quality and Their Effect on Performance in Service Companies Propositions and a Model," in Proceedings of the 1994 Academy of Marketing Science (AMS) Annual Conference, pp. 317-318, Springer International Publishing, 2015.

[9] K. C. Wei and T. M. Ling, "Relationships among service quality, corporate image, customer satisfaction, and behavioral intention for the elderly in high speed rail services," Journal of Advanced Transportation, vol. 47, no. 5, pp. 512-525, 2013.

[10] E. O. C. Mkpojiogu and N. L. Hashim, "Understanding the relationship between Kano model's customer satisfaction scores and self-stated requirements importance," SpringerPlus, vol. 5, no. 1, article no. 197, pp. 1-22, 2016.

[11] S. Chakraborty, K. Mengersen, C. Fidge, L. Ma, and D. Lassen, "A Bayesian Network-based customer satisfaction model: a tool for management decisions in railway transport," Decision Analytics, vol. 3, no. 1, 2016.

[12] W. Li, S. Yu, H. Pei, C. Zhao, and B. Tian, "A hybrid approach based on fuzzy AHP and 2-tuple fuzzy linguistic method for evaluation in-flight service quality," Journal of Air Transport Management, vol. 60, pp. 49-64, 2017.

[13] G. Büyüközkan and G. Çifçi, "A combined fuzzy AHP and fuzzy TOPSIS based strategic analysis of electronic service quality in healthcare industry," Expert Systems with Applications, vol. 39, no. 3, pp. 2341-2354, 2012.

[14] C.-C. Chou, L.-J. Liu, S.-F. Huang, J.-M. Yih, and T.-C. Han, "An evaluation of airline service quality using the fuzzy weighted SERVQUAL method," Applied Soft Computing, vol. 11, no. 2, pp. 2117-2128, 2011.

[15] C.-N. Liao and H.-P. Kao, "An evaluation approach to logistics service using fuzzy theory, quality function development and goal programming," Computers \& Industrial Engineering, vol. 68, no. 1, pp. 54-64, 2014.

[16] Z. Chongyang and F. Zhiping, "Optimization configuration of service elements in service design," Computer Integrated Manufacturing Systems, vol. 21, no. 11, pp. 3061-3071, 2015.

[17] A. Jamalnia, H. A. Mahdiraji, M. R. Sadeghi, S. H. R. Hajiagha, and A. Feili, "An integrated fuzzy QFD and fuzzy goal 
programming approach for global facility location-allocation problem," International Journal of Information Technology \& Decision Making, vol. 13, no. 2, pp. 263-290, 2014.

[18] C.-N. Liao, "Fuzzy analytical hierarchy process and multisegment goal programming applied to new product segmented under price strategy," Computers \& Industrial Engineering, vol. 61, no. 3, pp. 831-841, 2011.

[19] C.-H. Cheng, "A new approach for ranking fuzzy numbers by distance method," Fuzzy Sets and Systems, vol. 95, no. 3, pp. 307317, 1998.

[20] T.-C. Chu and C.-T. Tsao, "Ranking fuzzy numbers with an area between the centroid point and original point," Computers \& Mathematics with Applications, vol. 43, no. 1-2, pp. 111-117, 2002.

[21] D. Dubois and H. Prade, "Operations on fuzzy numbers," International Journal of Systems Science, vol. 9, no. 6, pp. 613626, 1978.

[22] T. C. Liu and L. I. Zhen-Fu, "Improved method of inconsistent interval reciprocal judgment matrix," Fuzzy Systems \& Mathematics, 2017.

[23] M. E. Sharpe, “The Loyalty Effect: The Hidden Force Behind Growth, Profits, and Lasting Value by Frederick F. Reichheld," Challenge, vol. 6, p. 60, 1996.

[24] E. Kim, W. Kim, and Y. Lee, "Combination of multiple classifiers for the customer's purchase behavior prediction," Decision Support Systems, vol. 34, no. 2, pp. 167-175, 2003.

[25] P. M. Guadagni and J. D. Little, "A Logit Model of Brand Choice Calibrated on Scanner Data," Marketing Science, vol. 2, no. 3, pp. 203-238, 1983.

[26] G. M. Coldren, F. S. Koppelman et al., "Air travel itinerary share prediction: Logit development at a major US airline," Journal of Air Transport Management, vol. 9, no. 6, pp. 361-369, 2003.

[27] H. Jiang, "A nested logit-based approach to measuring air shopping screen quality and predicting market share," Journal of Revenue and Pricing Management, vol. 8, no. 2-3, pp. 134-147, 2009.

[28] Y. P. Jiang, X. Liang, and J. Q. Yang, "Decision method for alternatives combination in service product design," Industrial Engineering and Managemen, vol. 19, no. 6, pp. 22-24, 2014.

[29] S. Gupta and R. Datta, "A methodology for component level improvement of passenger facilities at the Howrah railway station in India," TQM Journal, vol. 28, no. 3, pp. 496-526, 2016.

[30] S. Gupta and R. Datta, "Prioritizing service attributes for quality up-gradation of Indian railway stations," TQM Journal, vol. 24, no. 2, pp. 167-180, 2012.

[31] X. K. Jiang and X. Chen, "Research on prediction model of the impact of new telecom services tariff based on the customer choice behavior," Advanced Materials Research, vol. 765-767, pp. 3249-3252, 2013.

[32] R. Iyengar, K. Jedidi, S. Essegaier, and P. J. Danaher, “The impact of tariff structure on customer retention, usage, and profitability of access services," Marketing Science, vol. 30, no. 5, pp. 820-826, 2011. 


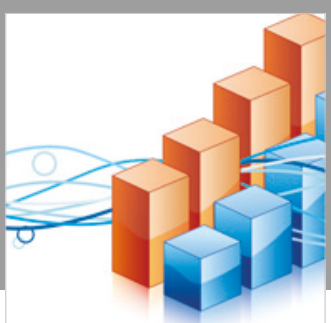

Advances in

Operations Research

\section{-n-m}
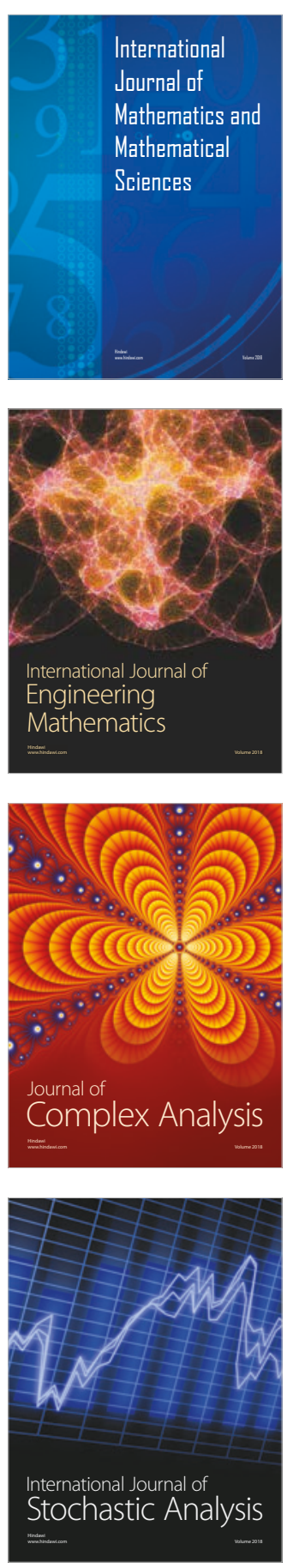


Journal of

Applied Mathematics
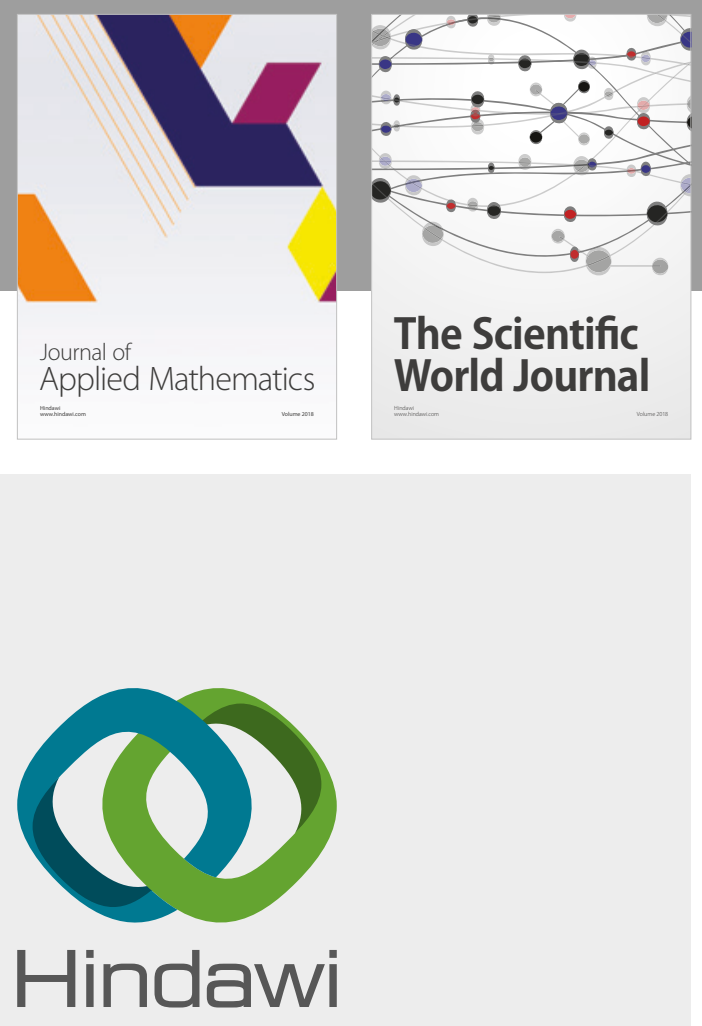

Submit your manuscripts at

www.hindawi.com



Advances in
Numerical Analysis
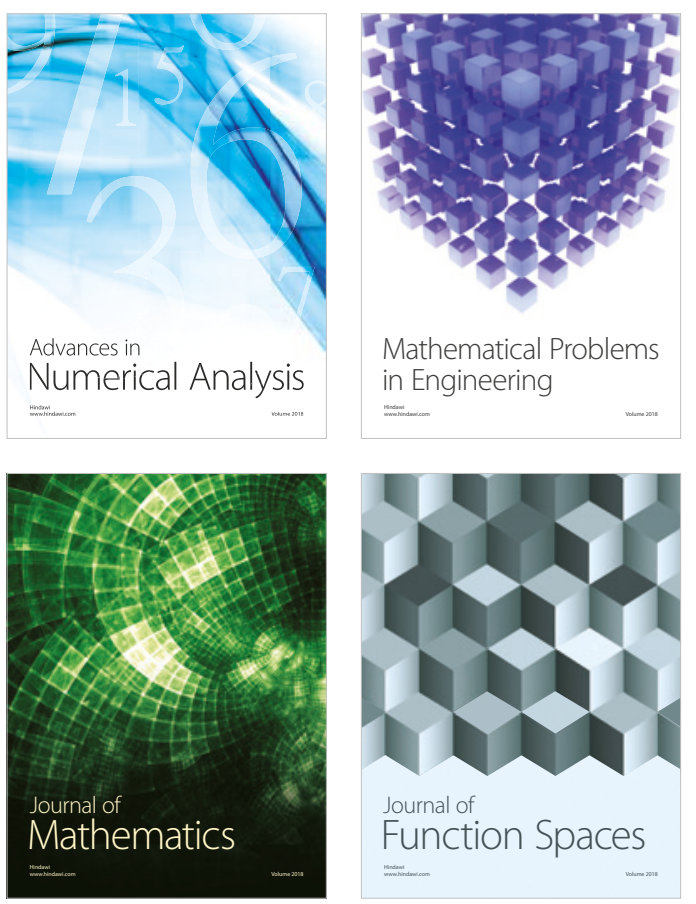

Mathematical Problems in Engineering

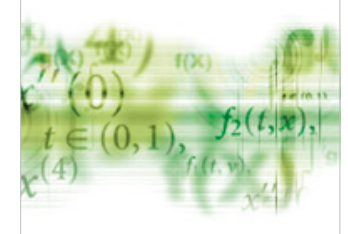

International Journal of

Differential Equations

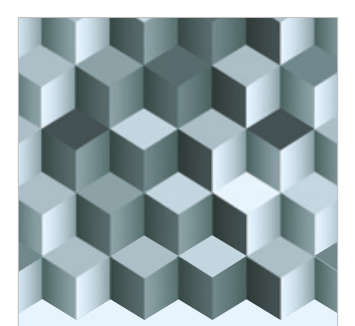

Journal of

Function Spaces

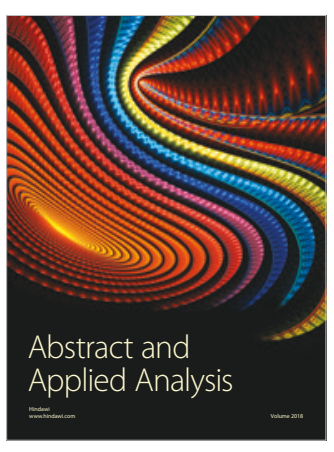

The Scientific

World Journal

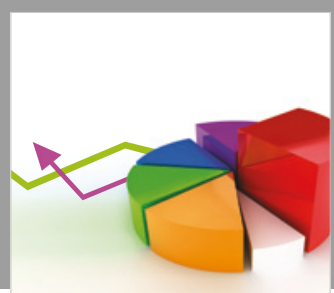

Journal of

Probability and Statistics
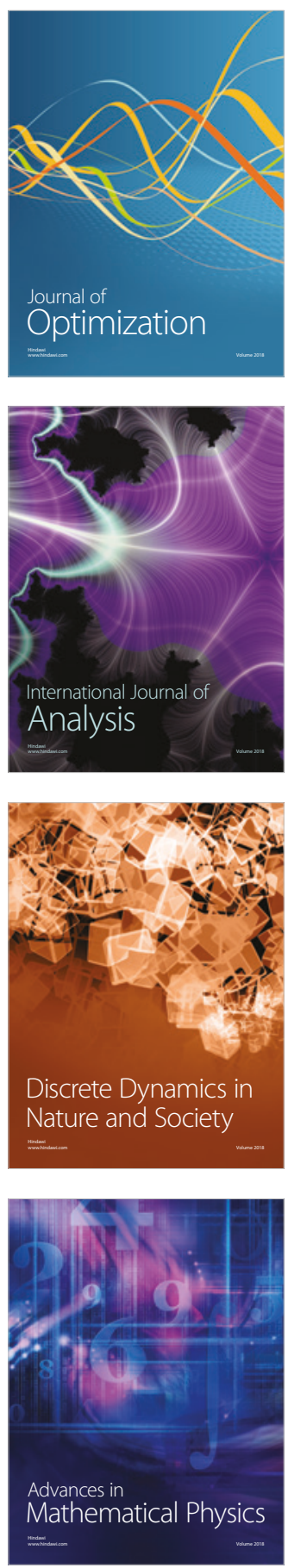